\title{
Development and Comparison of Skin Cancer Diagnosis Models
}

\author{
Emel Soylu ${ }^{1}$, Rukiye Demir ${ }^{2 *}$ \\ ${ }^{1}$ Samsun University, Faculty of Faculty of Engineering, Departmant of Software Engineering, Samsun, Turkey, (ORCID: 0000-0003-2774-9778), \\ emel.soylu@samsun.edu.tr \\ 2* Samsun University, Faculty of Faculty of Engineering, Departmant of Biomedical Engineering, Samsun, Turkey, (ORCID: 0000-0001-8761-9938), \\ rukiye.demir@samsun.edu.tr
}

(1st International Conference on Applied Engineering and Natural Sciences ICAENS 2021, November 1-3, 2021)

(DOI: 10.31590 /ejosat.1013910)

\begin{abstract}
ATIF/REFERENCE: Soylu, E., Demir, R (2021). Development and Comparison of Skin Cancer Diagnosis Models. European Journal of Science and Technology, (28), 1217-1221.
\end{abstract}

\begin{abstract}
Skin cancer is the uncontrolled growth of abnormal cells in the epidermis, the outermost layer of skin. The rapid growth and proliferation of abnormal cells creates malignant tumors of the skin. With the computer analysis of skin images, researchers are made to distinguish whether the skin spot is benign or malign It is automatically possible to classify whether a skin spot is benign or malignant by computer analysis of skin images. In this study, it was aimed to diagnose malignant skin images by computer analysis. The stained appearance on the skin is classified as benign or malignant using deep transfer learning techniques. Benign or malignant skin spot image data were used in network training. In image classification, darkNet-19, darkNet-53, squeezeNet, shufleNet architectures available in the Matlab deep learning toolbox were compared. High accuracy results have been obtained. The highest performance was achieved with the rate of $89.89 \%$ with darkNet-19 architecture. The performances of the networks darkNet-53, shuffleNet, squeezeNet architectures are $87.36 \%, 86.15 \%, 84.23 \%$ respectively.
\end{abstract}

Keywords: Skin cancer, Image classification, Deep learning.

\section{Cilt Kanseri Tanı Modellerinin Geliştirilmesi ve Karşılaştırılması}

\section{Öz}

Cilt kanseri, cildin en dış tabakası olan epidermisteki anormal hücrelerin kontrolsüz büyümesidir. Anormal hücrelerin hızlı büyümesi ve çoğalması, cildin kötü huylu tümörlerini oluşturur. Araştırmacılar, cilt görüntülerinin bilgisayar analizi ile cilt lekesinin iyi huylu veya kötü huylu olup olmadığını ayırt etmeye çalışırlar. Bu çalışmada malign cilt görüntülerinin bilgisayar analizi ile teşhis edilmesi amaçlanmıştır. Derideki lekeli görünüm, derin transfer öğrenme teknikleri kullanılarak iyi huylu veya kötü huylu olarak sınıflandırılır. Ağ eğitiminde iyi huylu veya kötü huylu cilt lekesi görüntü verileri kullanıldı. Görüntü sınıflandırmasında, Matlab derin öğrenme araç kutusunda bulunan darkNet-19, darkNet-53, squeezeNet, shufleNet mimarileri karşılaştırılmıştır. Yüksek doğrulukta sonuçlar elde edilmiştir. DarkNet-19 mimarisi ile en yüksek performans \%89,89 ile elde edilmiştir. DarkNet-53, shuffleNet, pinchNet mimarilerinin performansları sirasıly $\% 87,36, \% 86,15, \% 84,23$ 'tür.

Anahtar Kelimeler: Cilt kanseri, Görüntü sınıflandırması, Derin öğrenme.

\section{Introduction}

The skin on the human body plays an important role by covering all parts of the body such as muscles and bones. The skin consists of two layers, the upper epidermis, and lower dermis, and contains special structures such as hair follicles and sweat glands [1]. Thousands of people die from skin cancer every year [2],[3]. When diagnosed early, the 5-year survival rate is $99 \%$ [4]. The diseased spot on the skin is defined as skin lesion. There are a wide variety of skin lesions [5]. Benign skin lesions are common among them. These are sun-borne freckles, solar lentigines, melanocytic nevi, and seborrheic keratoses [6]. Not being protected from the harmful effects of the sun's rays or being exposed to the sun's rays for a long time are among the most important causes of skin cancer. According to a study, it was determined that skin cancer cases decreased during the COVID19 pandemic. This is because people are exposed to less sunlight [7].

Skin cancer is divided into melanoma and non-melanoma skin malignancies. It includes non-melanoma skin cancer (NMSC), basal cell carcinoma (BCC), and squamous cell carcinoma (SCC) [8]. With non-melanoma skin cancer patients, approximately two-thirds are basal cell carcinoma, one-third are cutaneous squamous cell carcinoma ( $\mathrm{cSCC}$ ) or other rare nonmelanoma skin cancers [9]. BCC and SCC are epithelial-derived 
skin cancer and share the same cell type [10]. Most melanomas are black due to the dark pigment of melanin. However, some melanomas appear in normal skin color, reddish and pinkish. BCC has many subcategories such as nodular BCC, superficial BCC, morpheaform BCC, basosquamous carcinoma. Their appearance varies from white to red [11].

Among the methods used in the early diagnosis of skin cancer; individual lesion or total body photographing dermoscopy, image analysis, and computer-aided diagnosis, multispectral imaging, confocal scanning laser microscopy, ultrasound, optical coherence tomography, and magnetic resonance imaging, and electrical resistance scanning system [12]. Dermatologists use dermatoscope to increase diagnostic reliability. Dermatoscope is a medical instrument that visualizes sub-surface structures of the skin that reveal lesion details in colors and tissues normally invisible to the naked eye [13]. The normal way to diagnose skin cancer is dermoscopic evaluation of the lesion, followed by biopsy and histopathological evaluation [14]. The diagnosis of diseases is generally determined by physicians using the biopsy method [5]. Many innovative skin cancer detection technologies have been developed to increase diagnostic accuracy for skin cancers [14].

The incidence of malignant skin tumors has increased significantly [15]. Early diagnosis and treatment are needed to reduce the number of deaths due to skin cancer. Because the prognosis improves when lesions are detected early for both melanoma and non-melanoma skin cancer [16].

Artificial intelligence techniques, which are used in many fields, are also successfully applied in the field of health [17], [18]. In recent years, various computer-aided diagnostic systems have been proposed for the detection of skin cancer. The $\mathrm{ABCD}(\mathrm{E})$ rule is a common method dermatologists use to diagnose skin cancer. In such methods, pattern analysis is performed using traditional feature extraction algorithms [13].

Image classification is one of the main problems of the computer vision field. Computer vision technology is used in many applications such as robotics, health, autonomous vehicles, object recognition. Machine learning has attracted attention, especially with its convolutional neural networks parasitism and success rate.

Architectures with a higher number of layers and neurons can be created by running artificial neural networks on graphics cards. These types of architectures are called deep neural networks (DNN). Thanks to deep learning techniques, results can be obtained without using the feature extraction process used in machine learning. High performance in image processing is achieved with DNN. An advantage of DNN is that it is possible to retrain previously trained and proven neural networks with new data. Deep learning architectures can also be used successfully in the early diagnosis of diseases in the field of health [19].

Researchers use deep learning-based transfer learning methods to detect skin cancer from images. In the skin cancer dermoscopy images classification study conducted by Lin et al., $87.3 \%$ success was achieved with DenseNet121 [20]. In a similar study, Mijwil achieved $87.66 \%$ success with the InceptionV3 architecture [21]. Layode et al. In their work on early skin cancer detection, they achieved $85 \%$ success with the integration of ResNet and VGG architectures [22]. Çevik ve Zengin achieved $85.62 \%$ success with VGGNET-16 architecture in their studies on the classification of skin lesions in dermatoscopic images [23].
In this study, the performances of previously trained DNN architectures darknet-19, darknet-53, squeezenet, shuflenet networks in benign and malign classification are compared. The best classification success rate is achieved by using Darknet-19 architecture.

In the continuation of this article, a dataset that is used in the diagnosis of skin cancer, methods that are used in the diagnosis of skin cancer, and the obtained results are discussed included.

\section{I.1 Data set}

We obtained the data from the online Kaggle online dataset sharing platform. The main source of the dataset is International Skin Imaging Collaboration (ISIC), an international effort to improve melanoma diagnosis [24]. The ISIC Archive contains the largest publicly available collection of quality-controlled dermoscopic images of skin lesions. In the data set, there are 1440 pictures of benign and 1197 malignant skin tumors with dimensions of $224 \times 224$ [25].70\% of the pictures in this data set were used in training and $30 \%$ in testing. Figure 1 gives examples of images diagnosed as malignant.

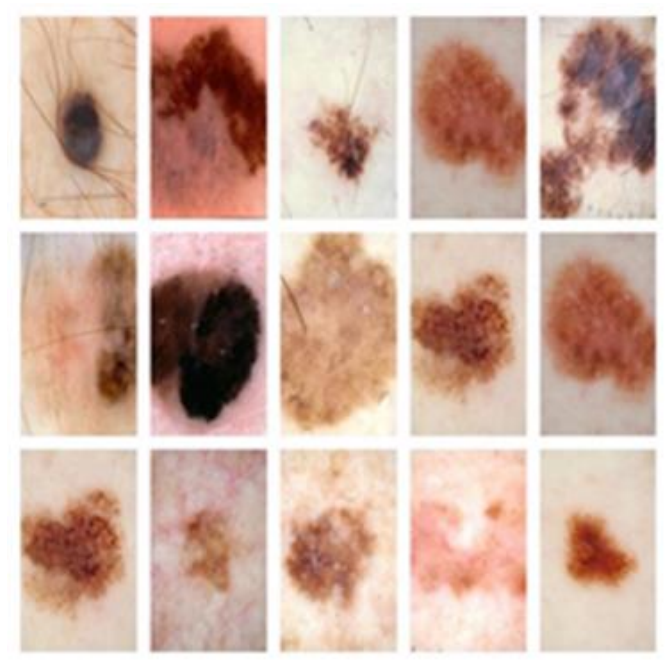

Figure 1. Images diagnosed as malignant [25].

In Figure 2, there are examples of benign images. Images were diversified with techniques such as rotation, mirroring, resizing before being used in network training.
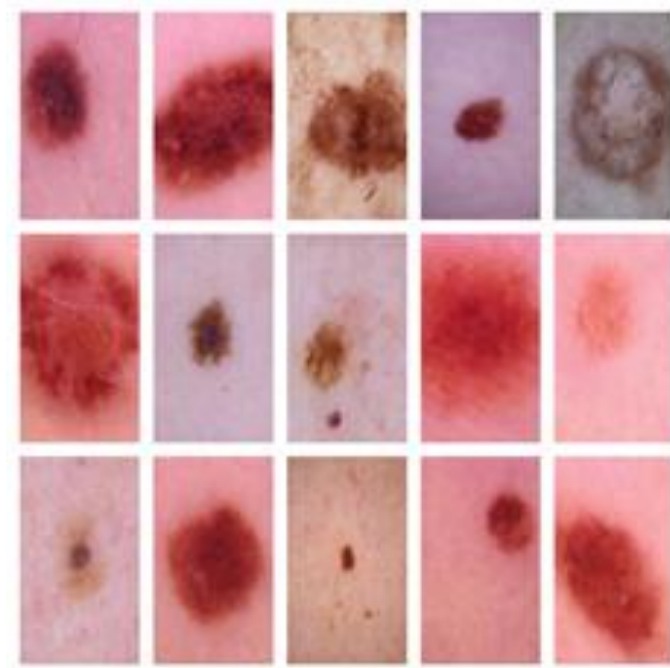

Figure 2. Benign skin blemishes images[25]. 


\section{Material and Method}

In this study, transfer-based deep learning methods were used by using 4 types of DNN architectures and Matlab "Deep Network Designer" application. darkNet-19, darkNet-53, squeezeNet, shuffleNet architectures were trained with the same learning algorithm, learning rate, and batch dimension. The block diagram of the system is given in Figure 3. The image applied to the DNN entry is classified as benign or malignant. DarkNet-19 is used as the backbone of YOLOv2 and is a 19-layer convolutional neural network. It mostly uses filters in layers and the number of channels doubles after each pooling step. It uses the global mean pool to make predictions as well as filters to compress the feature representation between convolutions. Batch normalization is used to stabilize the training, accelerate convergence, and organize the model set. [26]. The image input size of the network is $256 \times 256$. Figure 4 shows the accuracy rate graph depending on the number of iterations in the training process of the darkNet-19 network.
DarkNet-53 is a 53 layer-deep convolutional neural network that acts as a backbone for the YOLOv3 object detection approach. It has been improved with improvements in darkNet19. It involves the use of more layers [27]. The network has an image input size of $256 \times 256$. Figure 5 shows the accuracy rate graph depending on the number of iterations in the training process of the darkNet-53 network. SqueezeNet was developed at the University of California, Berkeley, and Stanford University, at DeepScale. When creating SqueezeNet, the researchers' goal was to create a smaller neural network with fewer parameters that required less computer memory and could be more easily transferred over a computer network [28]. It has a depth of 18 layers and an image input size of $227 \times 227$. Figure 6 shows the accuracy rate graph of the Squeezenet network depending on the number of iterations in the training process.

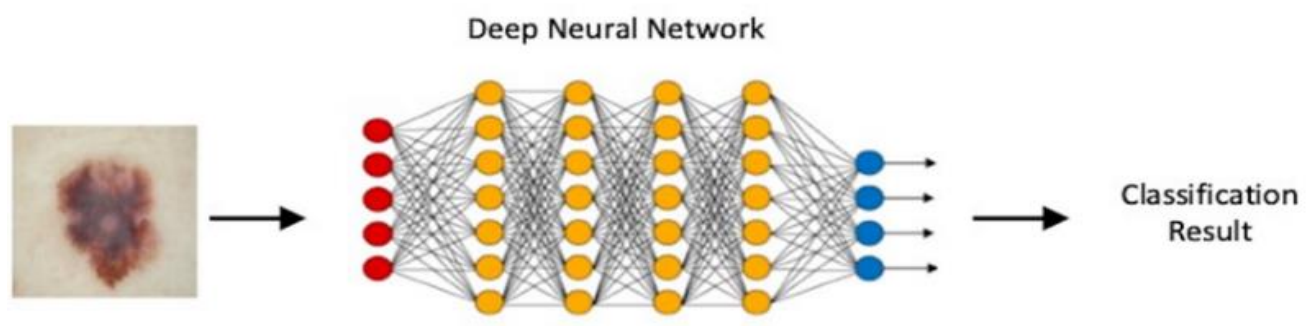

Figure 3. General working block diagram of the system.

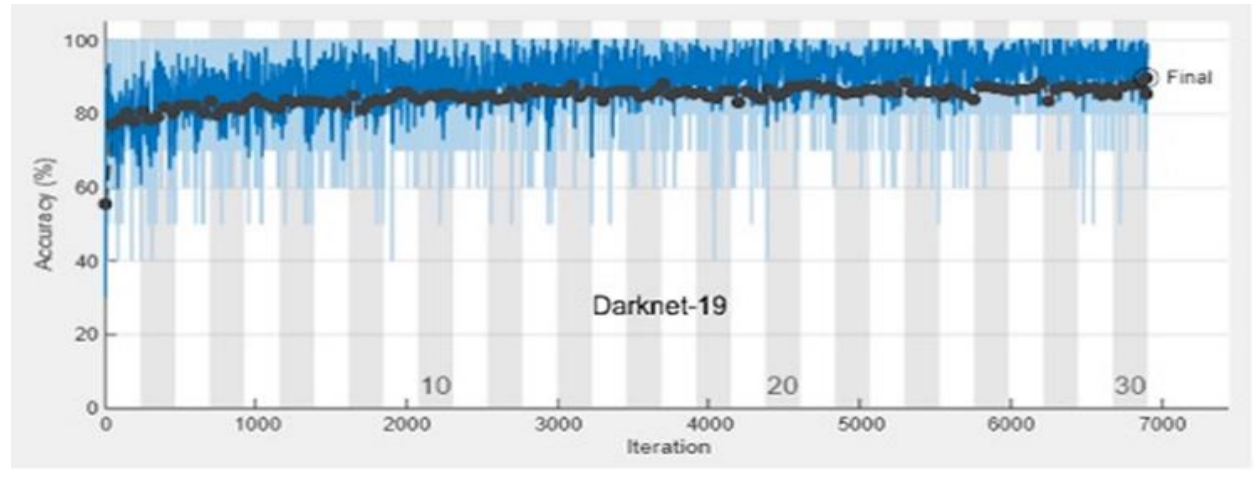

Figure 4. Darknet-19 re-training process

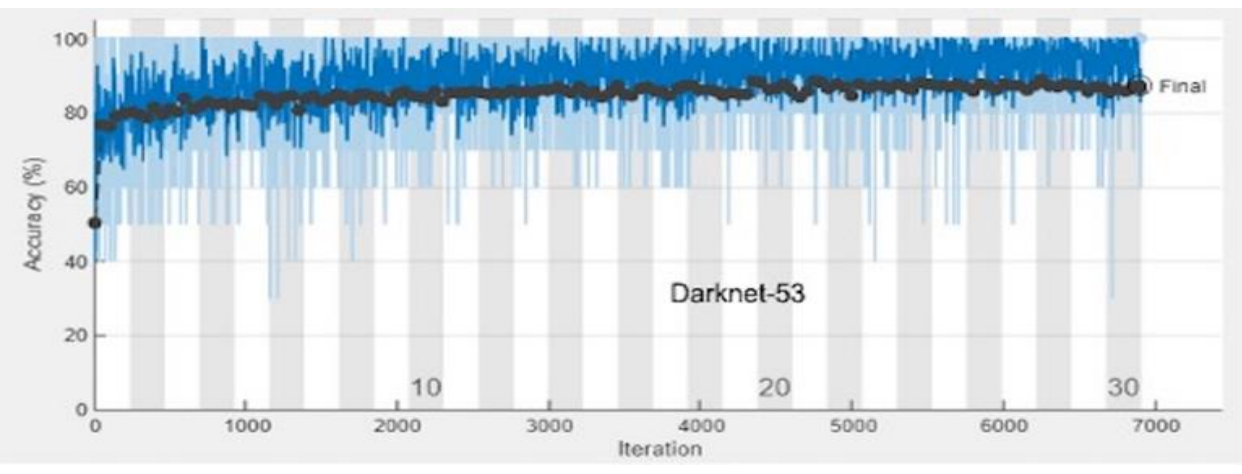

Figure 5. Darknet-53 re-training progress. 


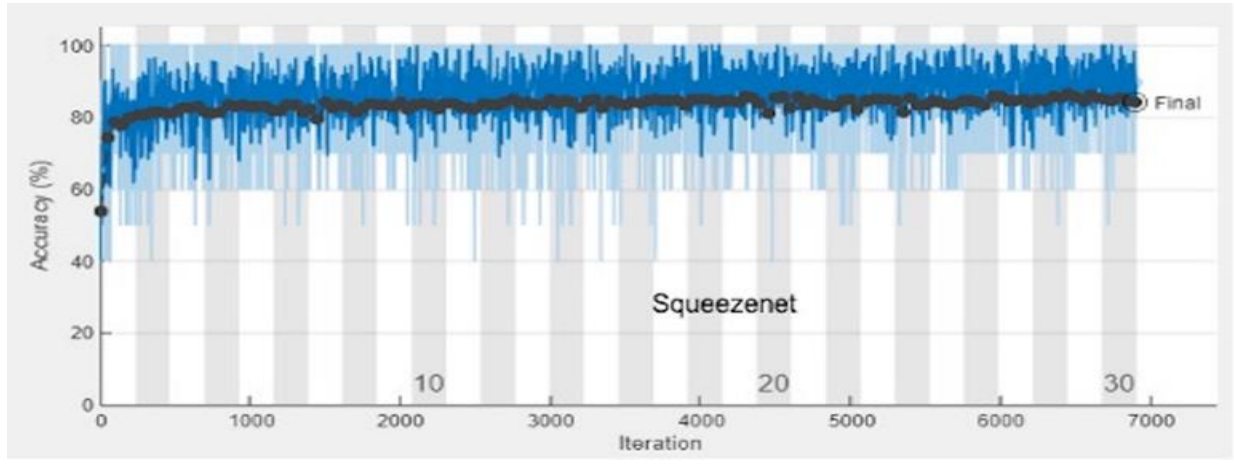

Figure 6.Squeezenet re-training process.

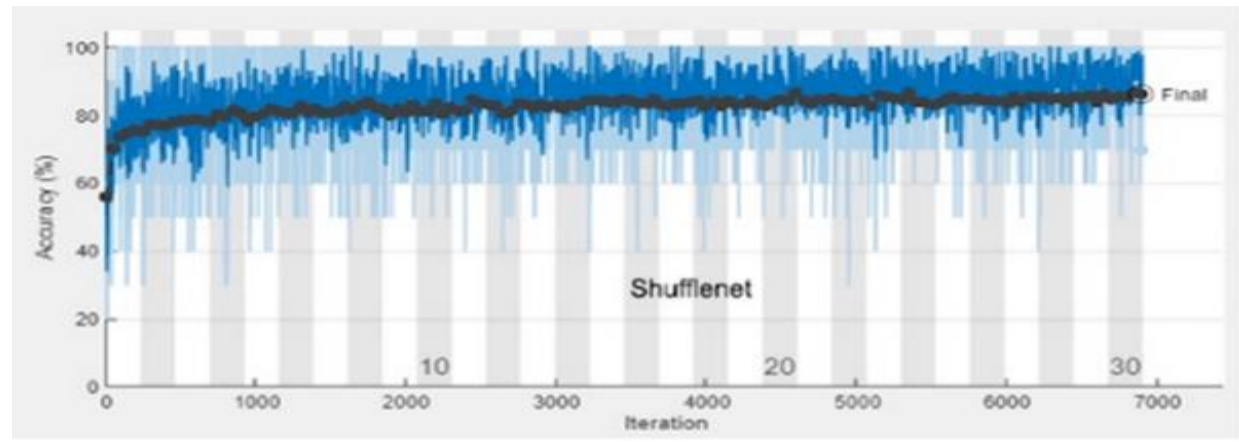

Figure 7. Shufflenet re-training process.

Table 2. Confusion matrix of classification

ShuffleNet architecture uses mixed grouped convolution, point grouped convolution and deeply separable convolution. This type of architectural design significantly reduces computational costs while maintaining accuracy [29]. It has a depth of 50 layers and an image size of $224 \times 224$. Figure 7 shows the accuracy rate graph of the Shufflenet network depending on the number of iterations in the training process.

In Table 1, the architecture used in the training process, learning rate, batch size, number of the epoch, number of iterations per epoch, learning time, and obtained accuracy rates are given. Confusion matrix of classification is given in Table 2.
Table 1. Comparison of architectures

\begin{tabular}{ccccccc}
\hline Architecture & $\begin{array}{c}\text { Learning } \\
\text { Rate }\end{array}$ & $\begin{array}{c}\text { Batch } \\
\text { Size }\end{array}$ & $\begin{array}{c}\text { Epoch } \\
\text { Number }\end{array}$ & $\begin{array}{c}\text { Learning } \\
\text { Algorithm }\end{array}$ & $\begin{array}{c}\text { Learning } \\
\text { time }\end{array}$ & $\begin{array}{c}\text { Accuracy } \\
\text { (\%) }\end{array}$ \\
\hline Darknet-19 & 0.0001 & 10 & 30 & sgdm & $\begin{array}{c}45 \mathrm{~min} \\
26 \mathrm{sec}\end{array}$ & 89.89 \\
\hline Darknet-53 & 0.0001 & 10 & 30 & sgdm & $\begin{array}{c}119 \mathrm{~min} \\
12 \mathrm{sec}\end{array}$ & 87.36 \\
\hline Squeezenet & 0.0001 & 10 & 30 & sgdm & $\begin{array}{c}27 \mathrm{~min} \\
58 \mathrm{sec}\end{array}$ & 84.23 \\
\hline Shufflenet & 0.0001 & 10 & 30 & $\mathrm{sgdm}$ & $\begin{array}{c}65 \mathrm{~min} \\
51 \mathrm{sec}\end{array}$ & 86.15 \\
\hline
\end{tabular}

\section{Results and Discussion}

Skin cancer is one of the causes of cancer-related death. As with many types of cancer, early detection saves lives. It can usually be prevented by going to a dermatologist regularly. It can have deadly results if neglected. In this study, it was tried to determine whether the skin spots were malignant or benign by image analysis. In image analysis, transfer learning based on darkNet-19, darkNet-53, squeezeNet, shuffleNet architectures was carried out. The highest performance was achieved with the rate of $89.89 \%$ in darkNet-19 architecture. Later, darkNet-53, shuffleNet, squeezeNet architectures with $87.36 \%, 86.15 \%$, $84.23 \%$ accuracy rates follow this performance rate. Future studies should focus on improving accuracy via combining methods. 


\section{Acknowledgement}

Thanks to Kaggle and the Author Claudio Fanconi, for providing the dataset of Skin Cancer: Malignant vs Benign images free online.

\section{References}

[1] Rognoni, E., \& Watt, F. M. (2018). Skin cell heterogeneity in development, wound healing, and cancer. Trends in cell biology, 28(9), 709-722.

[2] Fitzmaurice C, Akinyemiju TF, Al Lami FH, Alam T, Alizadeh-Navaei R, Allen C, et al. (2018)Global, regional, and national cancer incidence, mortality, years of life lost, years lived with disability, and disability-adjusted life-years for 29 cancer groups, 1990 to 2016: a systematic analysis for the global burden of disease study. JAMA Oncol.;4(11):1553-68.

[3] Dinehart, S. M. (2000). The treatment of actinic keratoses. Journal of the American Academy of Dermatology, 42(1), S25-S28.

[4] Skin Cancer Facts \& Statistics [Internet]. 2021. Available from: https://www.skincancer.org/skin-cancerinformation/skin-cancer-facts/

[5] Murugan, A., Nair, S. A. H., Preethi, A. A. P., \& Kumar, K. S. (2021). Diagnosis of skin cancer using machine learning techniques. Microprocessors and Microsystems, 81, 103727.

[6] Ogden E, Schofield J. (2013)Benign skin lesions. Medicine (Baltimore).;41(7):406-8.

[7] Andrew, T. W., Alrawi, M., \& Lovat, P. (2021). Reduction in skin cancer diagnoses in the UK during the COVID-19 pandemic. Clinical and Experimental Dermatology, 46(1), 145-146.

[8] Linares MA, Zakaria A, Nizran P. (2015) Skin Cancer. Prim CareClinics Off Pract.;42(4):645-59.

[9] Eigentler, T. K., Leiter, U., Häfner, H. M., Garbe, C., Röcken, M., \& Breuninger, H. (2017). Survival of patients with cutaneous squamous cell carcinoma: results of a prospective cohort study. Journal of Investigative Dermatology, 137(11), 2309-2315.

[10] Crowson, A. N. (2006). Basal cell carcinoma: biology, morphology and clinical implications. Modern pathology, 19(2), S127-S147.

[11]Goyal, M., Knackstedt, T., Yan, S., \& Hassanpour, S. (2020). Artificial intelligence-based image classification for diagnosis of skin cancer: Challenges and opportunities. Computers in Biology and Medicine, 104065.

[12] Özdemir F. (2007) Diagnosis of Melanoma. TURKDERM [Internet].;41(0):6-14. Available from: https://dx.doi.org/

[13]Pacheco, A. G., \& Krohling, R. A. (2020). The impact of patient clinical information on automated skin cancer detection. Computers in biology and medicine, 116, 103545.

[14]Dorrell, D. N., \& Strowd, L. C. (2019). Skin cancer detection technology. Dermatologic clinics, 37(4), 527-536.

[15]Holte, K., \& Biswas, A. (2017). Pathology of malignant skin tumours. Surgery (Oxford), 35(9), 478-483.

[16]Diepgen, T. L., \& Mahler, V. (2002). The epidemiology of skin cancer. British Journal of Dermatology, 146, 1-6.

[17] ŞENTÜRK, A., \& ŞENTÜRK, Z. K. (2016). Yapay Sinir Ağları İle Göğüs Kanseri Tahmini. El-Cezeri Journal of Science and Engineering, 3(2).
[18]Sivari E, Civelek Z, Kahraman G. (2020)Artificial neural network model estimating the initial dose of propofol used in general anesthesia. El-Cezeri J Sci Eng.;7(3):1482-95.

[19]Umut, K., Yılmaz, A., \& Dikmen, Y. (2019). Sağlık alanında kullanılan derin öğrenme yöntemleri. Avrupa Bilim ve Teknoloji Dergisi, (16), 792-808.

[20]Lin, T. C., \& Lee, H. C. (2020, December). Skin Cancer Dermoscopy Images Classification with Meta Data via Deep Learning Ensemble. In 2020 International Computer Symposium (ICS) (pp. 237-241). IEEE.

[21]Mijwil, M. M. (2021). Skin cancer disease images classification using deep learning solutions. Multimedia Tools and Applications, 1-17.

[22]Layode, O., Alam, T., \& Rahman, M. M. (2019, October). Deep Learning Based Integrated Classification and Image Retrieval System for Early Skin Cancer Detection. In 2019 IEEE Applied Imagery Pattern Recognition Workshop (AIPR) (pp. 1-7). IEEE.

[23]Çevik, E., \& Zengin, K. (2019). Classification of skin lesions in dermatoscopic images with deep convolution network. Avrupa Bilim ve Teknoloji Dergisi, 309-318.

[24]Codella NCF, Gutman D, Celebi ME, Helba B, Marchetti MA, Dusza SW, et al. Skin lesion analysis toward melanoma detection: A challenge at the 2017 International symposium on biomedical imaging (ISBI), hosted by the international skin imaging collaboration (ISIC). Proc - Int Symp Biomed Imaging. 2018;2018-April(Isbi):168-72.

[25]Skin Cancer: Malignant vs Benign [Internet]. Available from: https://www.kaggle.com/fanconic/skin-cancer-malignant-vsbenign

[26] Redmon, J., \& Farhadi, A. (2017). YOLO9000: better, faster, stronger. In Proceedings of the IEEE conference on computer vision and pattern recognition (pp. 7263-7271).

[27] Redmon, J., \& Farhadi, A. (2018). Yolov3: An incremental improvement. arXiv preprint arXiv:1804.02767.

[28] Iandola, F. N., Han, S., Moskewicz, M. W., Ashraf, K., Dally, W. J., \& Keutzer, K. (2016). SqueezeNet: AlexNetlevel accuracy with 50x fewer parameters and $<0.5 \mathrm{MB}$ model size. arXiv preprint arXiv:1602.07360.

[29] Zhang, X., Zhou, X., Lin, M., \& Sun, J. (2018). Shufflenet: An extremely efficient convolutional neural network for mobile devices. In Proceedings of the IEEE conference on computer vision and pattern recognition (pp. 6848-6856). 